\title{
DIREITO DE ACESSO À INFORMAÇÃO PÚBLICA E GOVERNO ELETRÔNICO: A TRANSPARÊNCIA NOS PORTAIS DO PODER EXECUTIVO DA ARGENTINA E DO BRASIL
}

\author{
RIGHT OF ACCESS TO PUBLIC INFORMATION AND ELECTRONIC \\ GOVERNMENT: TRANSPARENCY IN THE PORTALS OF THE \\ EXECUTIVE POWER OF ARGENTINA AND BRAZIL
}

\author{
Andrey Oliveira Lamberty \\ Universidade Federal de Santa Maria - UFSM - (Santa Maria, RS, Brasil) \\ Thais Bonato Gomes \\ Universidade Federal de Pelotas - UFPel - (Pelotas, RS, Brasil) \\ Rosane Leal da Silva \\ Universidade Federal de Santa Maria - UFSM - (Santa Maria, RS, Brasil) \\ Recebimento: 8 jul. 2019 \\ Aceitação: 21 nov. 2019
}

\begin{abstract}
Como citar este artigo / How to cite this article (informe a data atual de acesso / inform the current date of access):
LAMBERTY, Andrey Oliveira; GOMES, Thais Bonato; SILVA, Rosane Leal da. Direito de acesso à informação pública e governo eletrônico: a transparência nos portais do Poder Executivo da Argentina e do Brasil. Revista da Faculdade de Direito UFPR, Curitiba, PR, Brasil, v. 65, n. 1, p. 157-184, jan./abr. 2020. ISSN 2236-7284. Disponível em: <https://revistas.ufpr.br/direito/article/view/67912>. $\quad$ Acesso $\quad$ em: $\quad 30 \quad$ abr. $2020 . \quad$ DOI: http://dx.doi.org/10.5380/rfdufpr.v65i1.67912.
\end{abstract}

\section{RESUMO}

As Tecnologias da Informação e da Comunicação (TIC) possibilitam ao poder público a operacionalização de suas atividades mediante um governo eletrônico, permitindo que os cidadãos participem ativamente da administração pública por meio da plena eficácia do direito de acesso à informação. Visando regulamentar este direito, diversos países do mundo, como o Brasil e a Argentina, editaram leis de acesso à informação, que se encontram em diferentes estágios de avanço na consolidação desses regramentos. Diante disso, este artigo propõe-se a responder ao seguinte problema de pesquisa: Em que medida os sites do Poder Executivo argentino e brasileiro atendem às exigências de transparência delineadas pelas respectivas leis de cada país? Parte-se de um método de abordagem dedutivo e do método de procedimento comparativo aliado ao estudo de caso, utilizandose as técnicas de análise documental, pesquisa bibliográfica e elaboração de questionários, com o objetivo de verificar como se apresentam os portais institucionais dos principais ministérios e da presidência da república desses dois países à luz das orientações definidas pelas suas leis de acesso à informação (LAI). Os resultados apontam para o parcial cumprimento das LAI pelos portais ministeriais da Argentina e do Brasil e para o severo descumprimento delas pelos sites das presidências de ambas as nações. Além disso, aponta-se para a preocupante diminuição das pastas ministeriais nos dois países, o que deve ser visto com seriedade e atenção pelos cidadãos destas jovens democracias. 


\title{
PALAVRAS-CHAVE
}

Direito à informação. Governo eletrônico. Transparência.

\begin{abstract}
The Information and Communication Technologies (ICT) enable the public power to operate its activities through an electronic government, allowing citizens to participate actively in public administration through the full effectiveness of a right of access to information. In order to regulate this right, several countries in the world, such as Brazil and Argentina, have published information access laws, which are in different stages of progress in the consolidation of these regulations. Therefore, this article proposes to answer the following research problem: To what extent do the Argentine and Brazilian executive powers sites meet the transparency requirements outlined in the respective laws of each country? It is based on a method of deductive approach and the method of comparative procedure associated to the case study, using the techniques of documentary analysis, bibliographic research and questionnaire elaboration, with the objective of verifying how are presented the institutional portals of the main ministries and of the presidency of the republic of these countries in the light of the guidelines defined by their access to information laws. The results point to the partial fulfillment of the laws by the ministerial portals of Argentina and Brazil and to the severe noncompliance of them by the sites of the presidencies of both nations. In addition, there is a worrying decrease in ministerial portfolios in these two countries, which must be seen with seriousness and attention by the citizens of these young democracies.
\end{abstract}

\section{KEYWORDS}

Right to information. Electronic government. Transparency.

\section{INTRODUÇÃO}

A transparência da gestão pública é uma necessidade que se impõe a qualquer governo, especialmente quando se trata de um Estado democrático de direito. A evolução das Tecnologias da Informação e da Comunicação (TIC) permite a aproximação entre o poder público e seus governados, garantindo ao cidadão o acesso às informações de interesse público, o que lhe permite participar ativamente dos processos de tomada de decisões, controlar os gastos governamentais, fiscalizar e denunciar os atos de corrupção. Transparência e democracia caminham de mãos dadas, e as tecnologias informacionais são as ferramentas que garantem que essa abertura possa acontecer de forma eficaz.

O uso dessas tecnologias pela administração pública representa um salto de qualidade aos governos, elevando-os a um novo patamar, chamado de Governo Eletrônico (e-Gov), agregando inédito canal de transparência dos atos administrativos por meio da rede mundial de computadores. A evolução dessa modalidade de governo, com a participação ativa da sociedade por meio de um processo comunicativo de mão dupla, incorpora um avanço deste conceito, o de governança eletrônica, redefinindo a participação da sociedade civil e aprimorando os processos democráticos. 
Vale ressaltar que existe uma importante diferença conceitual entre governo eletrônico e governança eletrônica. “A governança é a maneira ou o processo de levar uma sociedade a melhor alcançar suas metas e interesses, enquanto o governo é a instituição ou o instrumento para realizar esse trabalho" (CRUZ-RUBIO, 2015, p. 133).

O autor mexicano César Nicandro Cruz-Rubio (2015, p. 133) explica que a governança eletrônica é mais do que a simples melhoria da eficiência governamental pelo uso das TIC, o que é atribuído ao governo eletrônico, mas a evolução dos processos de criação de valor público por meio da participação do cidadão nas decisões de interesse da sociedade e da promoção da transparência e eficácia governamental nesse processo, com a utilização das tecnologias informacionais. Isso implica reconhecer que a governança eletrônica estabelece um protocolo de comunicação de via dupla entre o governo e seus administrados (CRUZ-RUBIO, 2015, p. 134).

O direito de acesso à informação, inicialmente vinculado à liberdade de expressão, foi evoluindo historicamente até ser reconhecido como um direito fundamental autônomo pelos tratados internacionais de direitos humanos. Seguindo uma tendência observada mundialmente, diversos países da América Latina, entre eles o Brasil e, posteriormente, a Argentina, editaram leis de acesso à informação (LAIs), regulamentando este direito em seus territórios.

As LAI dos dois países estabelecem uma série de determinações a serem observadas pelos portais institucionais da administração pública, a fim de se adequarem às exigências mínimas de transparência. Partindo dessa evolução e tendo como base a perspectiva comparada, este estudo propõe-se a responder o seguinte problema de pesquisa: Em que medida os sites do Poder Executivo argentino e brasileiro atendem às exigências de transparência delineadas pelas respectivas leis de cada país?

Como aporte metodológico, emprega-se o método de abordagem dedutivo, que orienta o estudo desde os fundamentos do direito de acesso à informação até a observação dos portais do Poder Executivo. O método de procedimento utilizado combina estudo de caso e método comparativo, amparado pelas técnicas de análise documental, pesquisa bibliográfica e elaboração de questionários estruturados, a partir das quais foi realizada a observação direta, sistemática e não participante nos portais institucionais.

A pesquisa foi desenvolvida no âmbito do Núcleo de Direito Informacional (NUDI) da Universidade Federal de Santa Maria (UFSM), Santa Maria, Rio Grande do Sul. Assim, no projeto intitulado “O Estado na Sociedade em Rede: experiências democráticas de promoção de direitos fundamentais, acesso à justiça e transparência na América Latina e Caribe” delimitou-se o campo de pesquisa em seis países diferentes (Argentina, Brasil, Chile, Colômbia, Costa Rica e Uruguai), com 
a finalidade de analisar as experiências democráticas de acesso à informação, promoção da transparência na América Latina. Foram pesquisados os sites dos ministérios do Poder Executivo que tinham correspondência nessas nações, além do site da presidência da república de cada uma delas.

Partindo desse escopo mais amplo, este artigo busca divulgar os resultados da observação empreendida quanto ao Brasil e à Argentina, mais especificamente, com o objetivo de verificar como se apresentam os portais institucionais dos principais ministérios e da presidência da república dos dois vizinhos mercosulinos e, à luz das orientações definidas pelas respectivas leis de acesso à informação, analisar criticamente a efetivação da transparência ativa nesses países.

A escolha da Argentina como objeto do estudo comparado com o Brasil foi motivada pelo alto contraste existente entre os dois países quanto aos índices de corrupção e à confiança no governo. Conforme pesquisa realizada em 2018 pela organização sem fins lucrativos Latinobarómetro, o Brasil figura como o terceiro país latino-americano que mais considera a corrupção o seu problema mais importante (16\% dos resultados), enquanto a Argentina aparece entre os últimos colocados, com apenas 3\%. Além disso, com relação aos índices de confiança nas instituições, o Brasil aparece como o país com a menor taxa de confiança no governo (7\%), enquanto a Argentina apresenta resultado bem mais elevado (22\%) (LATINOBARÓMETRO, 2018).

Dessa forma, o artigo está articulado em dois capítulos: inicialmente, analisou-se o direito de acesso à informação e as políticas de governo eletrônico no Brasil e na Argentina, verificando-se quais são as determinações legais impostas à administração pública para o ajuste de seus portais aos padrões de transparência mínimos. E, em um segundo momento, partiu-se para a observação direta, sistemática e não participativa dos sites dos principais ministérios de cada país à época do estudo, realizado entre os meses de setembro e dezembro de 2018, bem como dos portais da presidência da república de ambas as nações.

\section{TRANSPARÊNCIA E GOVERNO ELETRÔNICO: A INSTRUMENTALIZAÇÃO DO DIREITO DE ACESSO À INFORMAÇÃO PÚBLICA NO BRASIL E NA ARGENTINA}

A informação pública é o único meio que permite ao cidadão tomar conhecimento dos assuntos de interesse da comunidade e participar da gestão de recursos públicos, mediante uma participação qualificada nos processos decisórios e na proposição de demandas. A divulgação dessa informação ao cidadão é um dever da administração pública, a ser cumprido da forma mais 
transparente possível pelo emprego de procedimento claro e facilitado, medidas que se impõem a um governo democrático.

O direito à informação consiste em um elemento indispensável para o pleno funcionamento de um Estado democrático de direito, na medida em que está “[...] solidamente fundado nos princípios da democracia, do bom governo e da participação cidadã” (ACKERMAN; SANDOVAL, 2005, p. 15, tradução nossa). A sua implementação permite um diálogo entre o povo e seus governantes, empoderando os cidadãos para lutar contra a corrupção e abusos do governo, o que somente é possível por meio de uma efetiva prestação de contas por parte do Estado (MENDEL, 2009, p. 1).

A participação cidadã em um Estado democrático de direito não é restrita aos processos eleitorais, ampliando-se as possibilidades de atuação por meio de audiências públicas, plebiscitos e apresentação de projetos de lei. O direito de acesso à informação, dessa forma, transcende o interesse individual para estabelecer os limites ao poder estatal, reduzindo a discricionariedade dos agentes públicos nos processos de tomada de decisões, o que permite o estabelecimento de uma nova forma de relacionamento entre o Estado e seus governados, pautada pela transparência (LAVALLE COBO, 2009, p. 34-35).

As Tecnologias da Informação e da Comunicação (TIC) favorecem o exercício desse direito, possibilitando ao Estado potencializar a transparência governamental, mediante a colocação à disposição da população de grande repositório de informações por meio de seus sites institucionais. Com isso, o poder público permite que a sociedade possua maior participação nos processos decisórios, por meio de escolhas esclarecidas e fundamentadas (LAVALLE COBO, 2009, p. 2). Esses processos de abertura e transparência, mediados pelo uso da internet, oxigenam a relação entre governo e sociedade civil, permitindo uma saudável participação cidadã na gestão pública.

No plano internacional, o ponto de partida para o reconhecimento do direito à informação enquanto um direito fundamental foi a Declaração Universal dos Direitos Humanos, assinada em 1948 pela Assembleia Geral das Nações Unidas (CENDEJAS JÁUREGUI, 2007, p. 58). O documento garante, em seu artigo 19 (ASSEMBLEIA GERAL DAS NAÇÕES UNIDAS, 1948), os direitos de liberdade de opinião e expressão, bem como de procurar, receber e transmitir informações - direitos que atualmente compõe uma concepção ampla do direito à informação.

Essa vinculação entre direito à informação e liberdade de expressão é uma característica marcante dos primeiros documentos internacionais que incorporaram esses direitos, observada

1 No original: “Aquí el derecho a la información está sólidamente fundado en los principios básicos de la democracia, el buen gobierno y la participación ciudadana”. 
também no artigo 19 do Pacto Internacional dos Direitos Civis e Políticos (ASSEMBLEIA GERAL DAS NAÇÕES UNIDAS, 1966), adotado pela Assembleia Geral das Nações Unidas em 1966, e no artigo 13 da Convenção Americana sobre Direitos Humanos (ORGANIZAÇÃO DOS ESTADOS AMERICANOS, 1969). Entretanto, não tardou para que se reconhecesse a autonomia do direito à informação, algo que foi acompanhado de uma forte tendência mundial no final do século XX, quando mais de quarenta países do mundo editaram suas leis de acesso à informação ${ }^{2}$ (ACKERMAN; SANDOVAL, 2005, p. 7).

Tamanha efervescência seguiu avançando no início deste século, inspirada, em grande medida, por importantes documentos internacionais, a exemplo da Declaração de Atlanta. Esse documento, firmado em 2008, resultou de uma conferência promovida pelo Carter Center, na qual participaram cento e vinte e cinco especialistas em Direito a informações públicas, oriundos de quarenta países. O texto trata o acesso à informação pública como um direito fundamental, constituindo-se em um marco ao incorporar importantes conceitos de transparência pública, devendo ser aplicado não somente aos órgãos públicos, mas também a atores não estatais que recebam fundos ou benefícios públicos de qualquer ordem. A inclusão das empresas privadas que também devem prestar informações públicas se constituiu em um importante avanço, até porque as estratégias de corrupção muitas vezes enlaçam instituições públicas, por meio de seus gestores, e empresas privadas, por intermédio de seus diretores, devendo-se pautar pelo reconhecimento de que o direito fundamental de acesso à informação pública é inerente a todas as culturas e sistemas de governo e que todos os Estados devem realizar ações específicas para assegurar esses direitos (CARTER CENTER, 2008).

Outro documento internacional importante é a Convenção das Nações Unidas contra a corrupção. Esse documento foi firmado no âmbito da Nações Unidas (ONU) em 2003 e pautou-se no reconhecimento de que a corrupção é um fenômeno de características globais e que ganha maior sofisticação com a intensificação das relações internacionais, que em certa medida também possibilitam a evasão de recursos provenientes de práticas ilícitas. Assim, preocupada com os efeitos nefastos que a corrupção pode trazer à população dos países, especialmente daqueles mais vulneráveis, a ONU adotou esse documento, que se divide em seções que cobrem aspectos de medidas preventivas, criminalização de condutas e aplicação da lei, formas de cooperação internacional e atuação para a recuperação de ativos. Destaque-se que o Brasil ratificou essa convenção em 31 de

2 A edição de uma lei para a regulamentação do acesso à informação teve iniciativa precursora da Suécia, em 1766, mediante a Freedom of Press and the Right of Access to Public Records Act (Lei da Liberdade de Imprensa e Direito de Acesso a Registros Públicos) (ACKERMAN; SANDOVAL, 2005, p. 13). 
janeiro de 2006, por meio do Decreto n. 5.687 (BRASIL, 2006). Conforme esse documento, os Estados Partes se comprometem a adotar políticas públicas contra corrupção, o que deve envolver tanto os atores públicos, quanto o setor privado e a sociedade (BRASIL, 2016b, p. 6-7).

Além das medidas preventivas, há também disposições referentes à criminalização de condutas, tipificando como crimes de corrupção: a) malversação ou peculato, apropriação indébita e outras formas de desvio de bens por um funcionário público; b) tráfico de influências; c) abuso de funções; d) suborno no setor privado; e) malversação ou peculato de bens públicos no setor privado; f) ocultação; e g) obstrução da justiça (BRASIL, 2016b, p. 8).

Um dos temas centrais desse documento é a previsão de cooperação internacional, especialmente necessária para possibilitar a recuperação de valores e bens obtidos por práticas corruptas e que tenham sido enviados indevidamente para fora do país; ou seja, é preciso que os países atuem de maneira articulada para a recuperação de ativos resultantes de atos de corrupção (BRASIL, 2016b, p. 9-10). A partir da internalização das normas relacionadas ao direito de acesso à informação previstas nesses instrumentos, Brasil e Argentina estabeleceram mecanismos regulatórios que impõem determinações à administração pública para o ajuste de seus portais aos padrões mínimos de transparência, que serão objetos de estudo dos pontos a seguir.

\subsection{A REGULAMENTAÇÃO DO ACESSO À INFORMAÇÃO NO BRASIL}

Apesar de todos os compromissos anteriormente elencados e do consenso internacional sobre a necessidade de combater a corrupção pela adoção de medidas de transparência, o Brasil ainda não contava com lei de acesso à informação pública, o que só veio a ocorrer em 2011, com a edição da Lei 12.527 (BRASIL, 2011), a qual regulamentou o artigo 5º inciso XXXIII da Carta Magna (BRASIL, 1988), propiciando ao cidadão o direito a exigir e a ser informado sobre dados públicos até então divulgados somente quando e como fosse interessante ao poder público. Ainda que a cultura do segredo seja um paradigma de difícil transposição, a lei assegura a publicidade como regra geral para a prestação de contas da administração pública no país, e o sigilo como exceção.

Quanto à transparência ativa, ou seja, a divulgação espontânea das informações públicas por parte dos órgãos e entidades governamentais, o artigo 3º , II, da Lei 12.527/2011 estabelece como diretriz a divulgação de informações de interesse público, independentemente de solicitações. Além disso, o artigo $8^{\circ}$, caput, determina o dever dos órgãos e entidades públicas na divulgação das informações de interesse público, em locais de fácil acesso, independentemente de requerimentos, 
sendo que o parágrafo $2^{\circ}$ do mesmo artigo prevê a obrigatoriedade da disponibilização das informações em sites oficiais da rede mundial de computadores (BRASIL, 2011).

No que se refere à transparência passiva, o artigo $10^{\circ}$, § $2^{\circ}$, da LAI brasileira prevê o dever dos órgãos e entidades do poder público em possibilitar o encaminhamento de pedidos de acesso por meio de seus sites oficiais na internet. Esse acesso foi assegurado pela criação do Serviço de Informação ao Cidadão (SIC), previsto no artigo 9, o qual possui a finalidade de atendimento, orientação e protocolo de documentos e requerimentos de acesso a informações (BRASIL, 2011).

Entretanto, o exercício da transparência ativa e passiva demanda do poder público a observância de alguns cuidados na divulgação da informação via internet, tais como a organização dos arquivos e a disponibilização em local de fácil acesso e localização dentro do site. Além disso, a informação disponibilizada deve ser dotada de algumas qualidades imprescindíveis, tais como: ser completa, adequada, atualizada, oportuna, compreensível e veraz (LAVALLE COBO, 2009, p. 1923).

As informações mínimas que devem constar nos sites institucionais da administração pública do Brasil foram discriminadas no artigo $8^{\circ}$, parágrafo $1^{\circ}$, da Lei 12.527/2011, e incluem o registro das competências e estrutura organizacional; endereços, telefones e horários de atendimento ao público; registros de repasses ou transferências de recursos financeiros; registros das despesas; procedimentos licitatórios e contratos celebrados; programas, ações, projetos e obras de órgãos e entidades; e respostas a perguntas frequentes (BRASIL, 2011).

A lei foi regulamentada pelo Decreto 7.724/2012, que estabeleceu, em seu artigo $7^{\circ}$, o padrão de disponibilização das informações nos sites de órgãos e entidades do Poder Executivo federal brasileiro. O modelo estabelecido pela Secretaria de Comunicação Social da Presidência da República inclui a disposição de banner na página inicial do site, que dará acesso a seção específica para a divulgação das informações de transparência, e uma barra de identidade do Governo Federal, contendo ferramenta que redireciona o usuário para a página do Portal Brasil e para o site sobre a Lei de Acesso à Informação (BRASIL, 2012).

A orientação é de que a seção de transparência dos portais contenha: 1) estrutura organizacional, competências, legislação aplicável, principais cargos e seus ocupantes, endereço, telefones e horários de atendimento; 2) programas, projetos, ações, obras e atividades, com indicação da unidade responsável, principais metas e resultados, além de indicadores de resultado e impacto; 3) repasses ou transferências financeiras; 4) execução orçamentária e financeira de forma detalhada; 4) licitações realizadas e em andamento, com editais, anexos e resultados, bem como contratos firmados e notas emitidas; 5) remuneração e subsídio recebidos por ocupante de cargo, posto, graduação, 
função e emprego público, incluídos os auxílios, ajudas de custo e proventos de aposentadoria e das pensões de servidores e empregados públicos na ativa; 6) respostas a perguntas mais frequentes; 7) contato da autoridade de monitoramento e telefone e e-mail do Serviço de Informações ao Cidadão SIC; e 8) programas financiados pelo Fundo de Amparo ao Trabalhador - FAT (BRASIL, 2012).

É importante, entretanto, apontar uma falha na legislação brasileira, que pode comprometer a efetividade dos dispositivos anteriormente listados: o extenso rol de exceções ao acesso à informação. Enumerando-se os enunciados legais, é possível listar: i) as hipóteses de sigilo previstas na legislação (sigilo fiscal, bancário, comercial, etc.); ii) informações referentes a projetos de pesquisa e desenvolvimento científicos ou tecnológicos, cujo sigilo seja imprescindível à segurança da sociedade e do Estado (art. 6º I e II, do Decreto 7.724/2012) (BRASIL, 2012); iii) informações classificadas em grau de sigilo (art. 23 da LAI), dentre as quais a lei elenca oito situações, em grande parte relacionadas à defesa nacional e à segurança pública; e iv) informações pessoais relativas à intimidade, vida privada, honra e imagem (artigo 31 da LAI) (BRASIL, 2011). Essa ampliação demasiada pode ser utilizada para acobertar a falta de esclarecimento sobre situações de evidente interesse público, já que os critérios de classificação acabam não sendo expostos de forma clara aos cidadãos.

Não se pode esquecer que a utilização das plataformas digitais pela administração pública, como forma de operacionalizar a transparência governamental e os processos democráticos, coadunase ao conceito de Governo Eletrônico (ou e-Gov), qual seja, “[...] uma infra-estrutura única de comunicação compartilhada por diferentes órgãos públicos a partir da qual a tecnologia da informação e da comunicação é usada de forma intensiva para melhorar a gestão pública e o atendimento ao cidadão” (ROVER, 2006, p. 99). Trata-se, portanto, de uma aplicação das TIC com vistas a melhorar a comunicação entre governo e cidadãos, visando uma administração mais eficiente (CRUZ-RUBIO, 2015, p. 132).

O Governo Eletrônico teve seu marco inaugural no Brasil com a edição do Decreto Presidencial de 3 de abril de 2000, que instituiu o Grupo de Trabalho Interministerial (Grupo de Trabalho em Tecnologia da Informação - GTTI) com o objetivo de examinar e sugerir políticas, diretrizes e normas relacionadas às novas formas eletrônicas de interação (BRASIL, 2000). A atuação do GTTI voltou-se especialmente a três linhas do programa: universalização de serviços, governo ao alcance de todos e infraestrutura avançada, criando, em outubro do mesmo ano, o Comitê Executivo de Governo Eletrônico (CEGE), que visava ao estabelecimento de políticas e diretrizes e a articulação das ações de implantação do Governo Eletrônico (BRASIL, 2019f). 
Quatro anos mais tarde, criava-se o Departamento de Governo Eletrônico, por meio do Decreto $n^{\circ}$ 5.134/2004, cuja função primordial era a de implantação de ações integradas de governo eletrônico no país, coordenando as atividades relacionadas à prestação de serviços públicos pela utilização das tecnologias informacionais, bem como o desenvolvimento de ações de governo eletrônico no âmbito da administração pública federal (BRASIL, 2019f).

Em 2016, a publicação do Decreto nº 8.638 instituiu a Política de Governança Digital no âmbito da administração pública federal direta, autárquica e fundacional brasileira, visando à geração de benefícios para a sociedade por meio do uso das tecnologias da informação e comunicação na prestação de serviços públicos e ao incentivo à participação dos cidadãos na criação, implementação, monitoramento e avaliação das políticas públicas e serviços públicos disponibilizados digitalmente, assegurando-se a obtenção de informações pela sociedade, com a ressalva das limitações legalmente impostas (BRASIL, 2016a).

Esse avanço legislativo busca agregar inédito canal de transparência dos atos administrativos por meio da internet, redefinindo a participação da sociedade civil e aprimorando os processos democráticos, o que nem sempre reflete nas práticas governamentais. Como visto, a lei de acesso à informação brasileira inverteu a lógica do sigilo administrativo, atribuindo à publicidade a condição de regra, instituiu os deveres de transparência ativa e passiva à administração pública, criando canais de abertura ao cidadão e dispôs sobre os padrões mínimos a serem implementados nos portais institucionais, tais como programas, ações e projetos, registros de despesas e transferências de recursos financeiros, procedimentos licitatórios e contratos celebrados.

Ainda que apresente uma quantidade preocupante de exceções à regra da publicidade, a lei institui diretrizes, para implementação pelos organismos públicos, que se mostram extremamente salutares diante da urgente necessidade de abertura do poder público, já que o advento das novas tecnologias informacionais não pode ser uma via de mão única, permitindo ao cidadão ser vigiado silenciosamente em todos os seus movimentos (BAUMAN; LYON, 2013) enquanto oculta o governo de seu povo, especialmente em Estados que se dizem democráticos, como o brasileiro. Cabe, portanto, aos órgãos governamentais a implementação da abertura enunciada pela LAI, tornando efetivas as disposições legais. Semelhante processo vem sendo enfrentado na Argentina, que conta com uma novel legislação disciplinando o direito de acesso à informação pública, cujas disposições serão analisadas no tópico seguinte. 


\subsection{TRANSPARÊNCIA PÚBLICA NA LEGISLAÇÃO ARGENTINA}

Na Argentina, a edição do Decreto 378, de 27 de abril de 2005, representou o marco inicial para o estabelecimento de uma política efetiva de governo eletrônico no país (MARTINUZZO, 2008). O decreto delineou as diretrizes que regem o Plano Nacional de Governo Eletrônico e os Planos Setoriais de Governo Eletrônico dos órgãos da administração pública do país, definindo como princípios orientadores a melhoria do serviço ao cidadão, a melhor gestão pública, a redução de custos, a transparência, a participação, a integração, o apoio ao desenvolvimento e a integração à economia mundial (ARGENTINA, 2005).

No âmbito do Plano Nacional de Governo Eletrônico, o Decreto 378/2005 estabelece, em seu artigo $5^{\circ}$, diversos programas a serem adotados pelos órgãos vinculados ao poder público argentino, visando à transparência na divulgação de seus atos, quais sejam: a) guia de trâmites, facilitando ao cidadão o acesso aos procedimentos de forma compreensível e precisa; b) portal geral do Governo da República Argentina, permitindo via internet o acesso a informações da administração pública de forma ágil e simples; c) sistema de monitoramento de expedientes, possibilitando a consulta de trâmites pela rede; d) janela única para o cidadão, coordenando ações em nível provincial, municipal e nacional e com organizações da sociedade civil; e) portais temáticos do Governo da República Argentina, contendo links relacionados a cada uma das informações publicadas por diferentes organismos disponíveis na internet; f) diretório on-line dos organismos e funcionários da administração pública nacional, disponibilizando na internet os números de telefone, e-mail e endereço físico de todos os organismos que compõem a administração pública e seus responsáveis (ARGENTINA, 2005).

Ainda que exista tal previsão, observa-se que a divulgação de informações pela administração pública argentina encontra-se, há algum tempo, em um processo assimétrico, variável de acordo com a instituição, o que evidencia a ausência de uma estratégia comunicacional integrada (LAVALLE COBO, 2009, p. 2). Talvez isso se deva ao fato de que a Argentina permaneceu por muitos anos sem uma regulamentação para o direito de acesso à informação, vindo a editar a sua tão aguardada lei de acesso à informação somente no ano de 2016.

Apesar de a Constituição da Nação Argentina de 1853 não ter contemplado expressamente o direito de acesso à informação, garantindo apenas a liberdade de imprensa em seus artigos 14 e 32, a reforma constitucional de 1994 outorgou caráter constitucional aos Tratados Internacionais de Direitos Humanos (ALFARO, 2013, p. 6), elencando-os no artigo 75, inciso 22, entre os quais 
encontra-se a própria Declaração Universal dos Direitos Humanos, primeiro documento a assegurar esse direito fundamental.

Além disso, o artigo 33 reconhece a existência de outros direitos não enumerados pela carta magna, que deverão ser igualmente protegidos. Outros artigos inseridos pela reforma constitucional de 1994 tratam do direito de acesso à informação voltado a temas específicos, tais como a informação ambiental (artigo 41) e a informação no âmbito do consumo (artigo 42) (ARGENTINA, 1994).

Em 2003 foi editado o Decreto Presidencial 1.172, que estabeleceu mecanismos de acesso à informação no âmbito do Poder Executivo Nacional da Argentina, representando um importante avanço rumo à edição de uma lei específica sobre o tema no país, na medida em que respeitou as normas internacionais que dispõem sobre a matéria (OYHANARTE; KANTOR, 2015, p. 259). O decreto prevê, em seu anexo VII, o Regulamento Geral de Acesso à Informação Pública para o Poder Executivo Nacional, que apresenta desde os princípios norteadores até os requisitos para a solicitação de informações, visando "permitir e promover uma efetiva participação cidadã, por meio da prestação de informação completa, adequada, oportuna e veraz”3 (ARGENTINA, 2003, tradução nossa).

A espera por uma lei que regulamentasse o acesso à informação de um modo geral, abrangendo Poder Executivo, Legislativo e Judiciário teve fim em 14 de setembro de 2016, com a edição da Lei 27.275. Essa lei tem por objetivo a garantia de um efetivo exercício do direito de acesso à informação pública no país, com a promoção da participação dos cidadãos na tomada de decisões e da transparência da gestão pública, fundando-se em princípios como a presunção de publicidade, transparência e máxima divulgação, abertura, não discriminação e gratuidade (ARGENTINA, 2016).

No que se refere à transparência passiva, o artigo $9^{\circ}$ da LAI argentina garante a possibilidade de solicitação de informações por escrito ou por meios eletrônicos, sem qualquer formalidade, bastando a identificação e os dados de contato do solicitante e a identificação clara da informação solicitada. A solicitação deverá ser respondida pela administração pública no prazo de quinze dias úteis, prorrogáveis por igual período caso haja circunstâncias que dificultem a reunião da informação solicitada, nos termos do artigo 11 (ARGENTINA, 2016).

Quanto à divulgação proativa das informações pelo poder público (transparência ativa), o artigo 32 determina que os sujeitos obrigados deverão facilitar a busca de informações pela internet, de maneira clara, estruturada e compreensível aos interessados, removendo as barreiras que possam obstaculizar a sua reutilização por terceiros. Os portais institucionais devem conter informações

3 No original: “ARTICULO $4^{\circ}$ - FINALIDAD La finalidad del Acceso a la Información Pública es permitir y promover una efectiva participación ciudadana, a través de la provisión de información completa, adecuada, oportuna y veraz". 
completas e atualizadas, em formato digital e dados abertos (ARGENTINA, 2016), o que visa tornar possível a manipulação desses dados pelo interessado.

As diretrizes a serem seguidas pelos órgãos da administração pública argentina, listadas nos incisos do artigo 32 da LAI, incluem a publicação das seguintes informações em seus sites: a) índice da informação pública em seu poder; b) organograma e funções; c) lista de autoridades, funcionários permanentes e temporários ou outras modalidades de contratação; d) escalas salariais correspondentes a todas as categorias de contratados; e) orçamento de cada área, programa ou função; f) transferências de fundos; g) lista de contratos públicos, licitações, concursos, obras públicas e aquisições de bens e serviços; h) todo ato ou resolução que estabeleça benefícios para o público em geral ou para um setor específico; i) relatórios de auditorias ou avaliações; j) permissões, concessões e autorizações concedidas; k) serviços prestados diretamente ao público; l) procedimento para a apresentação de petições e o acesso de informações; m) autoridade competente para receber os pedidos de informações; n) índice de trâmites e procedimentos executados perante o organismo; o) mecanismos para a apresentação de solicitações com relação a ações ou omissões do sujeito obrigado; p) guia com informações sobre a manutenção de documentos, tipos e categorias de informações que publicam; q) acordos, resoluções e sentenças que estejam obrigados a publicar por força de lei; r) informações relacionadas às solicitações mais frequentes; s) depoimentos dos sujeitos obrigados; t) qualquer outra informação considerada relevante para o exercício do direito de acesso à informação pública (ARGENTINA, 2016).

Assim como a LAI brasileira, a lei argentina também apresenta um excessivo rol de exceções ao fornecimento de informações pelos sujeitos obrigados (treze hipóteses no total - art. $8^{\circ}$ ), entre as quais se inclui a informação classificada como reservada, confidencial ou secreta por razões de defesa ou política exterior; a informação que possa colocar em perigo o funcionamento do sistema financeiro ou bancário; segredos industriais, comerciais, financeiros, científicos, técnicos ou tecnológicos; informação que comprometa os direitos ou interesses legítimos de um terceiro, obtida em caráter confidencial; informação que possa causar perigo à vida ou à segurança de um indivíduo, etc. A lei deixa claro, em seu artigo 34, que as exceções previstas no artigo $8^{\circ}$ serão aplicadas para os fins de transparência ativa pelos órgãos públicos no cumprimento das diretrizes elencadas no artigo 32, ou seja, essas hipóteses não integram as informações que deverão ser divulgadas na rede mundial de computadores (ARGENTINA, 2016).

A ampliada gama de previsões que excepcionam o dever de transparência dos órgãos públicos, tal como ocorre no Brasil, implica uma tendência à continuidade de práticas ocultas legalmente justificadas, já que, em muitos casos, a abertura semântica dos dispositivos permite o 
abrigo das mais variadas situações, o que esvazia o objetivo legal. Em comparativo com a LAI brasileira, a lei argentina apresenta um número ainda mais extenso de exceções, incluindo hipóteses não previstas na lei do Brasil, tais como o comprometimento de direitos ou interesses legítimos de terceiro, e o caso das informações destinadas a regular ou supervisionar a situação de instituições financeiras.

Ainda que existam falhas, o modelo argentino reflete um recente esforço legislativo pela inclusão do país no rol daqueles que contam com leis regulamentadoras do acesso à informação no mundo, já que até então o principal marco normativo do país era o Decreto Presidencial 1.172, de 2003, que disciplinava o acesso à informação somente no âmbito do Poder Executivo Nacional. Apesar de ser uma legislação ainda não consolidada, cuja implementação avança em seus primeiros passos, especialmente em comparação à legislação brasileira, já sedimentada, a nova Lei de Acesso à Informação da Argentina estabelece de forma satisfatória os mecanismos para a efetivação da transparência ativa e passiva por parte do poder público, seja com o acesso facilitado às informações produzidas ou gerenciadas pelo Estado, por meio de diretrizes que impõe ao Estado diversas medidas a serem adotadas em seus sites, ou pela disponibilização de instrumentos de consulta pública, apresentando um nível adequado e compatível à LAI do Brasil.

Com isso, a administração pública dos dois países assume a tarefa de concretização dos preceitos legais a partir da adaptação de seus portais institucionais na rede mundial de computadores, ampliando as condições do cidadão de participar de forma efetiva da gestão governamental, desafio que se impõe para uma necessária transposição da cultura do sigilo, arraigada nas instituições públicas da América Latina - não é à toa que Brasil e Argentina elencam um amplo catálogo de situações excluídas do âmbito do dever de transparência governamental, evidenciando a manutenção de um paradigma que precisa ser revisto a partir da iniciativa do cidadão, buscando a efetivação de um direito de acesso à informação, fundamental para o debate salutar e a participação informada em um Estado democrático de direito.

Todas as categorias elencadas ao longo deste capítulo, tanto no que se refere à legislação brasileira quanto à argentina, visam delinear um patamar mínimo de transparência a ser atingido pelos sujeitos obrigados em suas políticas de acesso à informação, com informações que devem integrar as páginas dos portais institucionais de forma completa, atualizada e em local de fácil acesso ao usuário - critérios que nem sempre são observados na prática. Portanto, a fim de identificar como é exercida, efetivamente, a transparência nos órgãos da administração pública dos dois vizinhos mercosulinos, parte-se para uma observação dos sites do Poder Executivo dos dois países, realizada sob uma perspectiva comparada, o que será apresentado no capítulo seguinte. 


\section{A TRANSPARENCIA NOS PORTAIS DO PODER EXECUTIVO DA ARGENTINA E DO BRASIL: APONTAMENTOS SOBRE OS SITES INSTITUCIONAIS DOS MINISTÉRIOS E DA PRESIDÊNCIA DA REPÚBLICA}

O estudo comparado foi desenvolvido com o intuito de analisar as experiências democráticas de acesso à informação, promoção da transparência e efetividade de direitos fundamentais a partir do uso das TIC, pesquisando-se os sites dos ministérios do Poder Executivo e da presidência da república do Brasil e da Argentina, em específico. A partir do estudo de caso e do método comparativo, amparado pelas técnicas de análise documental, pesquisa bibliográfica e elaboração de questionários, realizou-se a observação direta e sistemática dos portais, com o objetivo de preenchimento de um formulário online construído com base nos requisitos da LAI brasileira ${ }^{4}$. Para a construção de tal instrumento foram considerados os dados quantitativos e qualitativos a respeito da aplicabilidade da lei de acesso à informação no Poder Executivo dos respectivos Estados.

Nesse sentido, efetuando-se o recorte do Brasil e da Argentina, em termos quantitativos, foram analisados o total de dezenove sites de ministérios do Poder Executivo argentinos e dezoito sites de ministérios do Poder Executivo brasileiros, além do portal da presidência da república de cada um deles, investigados no período de março a dezembro de 2018. A fim de ilustrar em que medida os portais do Poder Executivo desses países mercosulinos estão atendendo às exigências de transparência delineadas pelas respectivas leis de cada país, apuram-se, em linhas gerais, os resultados extraídos do estudo de caso desenvolvido no ano de 2018, salientando as extinções e incorporações de ministérios e o preenchimento dos requisitos basilares das LAI.

\subsection{A APLICABILIDADE DA LEI BRASILEIRA NOS PORTAIS DO PODER EXECUTIVO}

Primeiramente, a respeito do âmbito brasileiro, estabeleceu-se como meta o estudo dos seguintes portais: Ministério da Educação; Ministério da Saúde; Ministério da Indústria, Comércio Exterior e Serviços; Ministério da Defesa; Ministério da Ciência, Tecnologia, Inovações e Comunicações; Ministério da Justiça; Ministério da Agricultura, Pecuária e Abastecimento; Ministério dos Transportes, Portos e Aviação Civil; Ministério do Turismo; Ministério da Fazenda;

4 O formulário foi desenvolvido por meio do aplicativo Google Forms ${ }^{\circledR}$ (GOOGLE, 2019), sendo composto por 24 quesitos, elaborados a partir das diretrizes delineadas no Decreto 7.724/2012 (BRASIL, 2012), tais como a existência de seção específica sobre a LAI, informações institucionais, ações e programas, auditorias, convênios, despesas, licitações e contratos, servidores, perguntas frequentes, legislação sobre a Lei de Acesso à Informação, Serviço de Informação ao Cidadão - SIC, informações classificadas, participação social, dados abertos e receitas, etc. 
Ministério das Relações Exteriores; Ministério de Minas e Energia; Ministério do Planejamento, desenvolvimento e gestão; Ministério do Trabalho; Ministério do Desenvolvimento Social; Ministério da Cultura; Ministério do Esporte; Ministério do Meio Ambiente e, por fim, o Portal da Presidência da República.

Da análise geral desses sites, constata-se que a responsabilidade por disponibilizar os dados, que deveria ser dos portais dos ministérios, é transferida ao Portal da Transparência, à medida que, usualmente, os sites brasileiros remetem a esse portal. Assim, a análise limita-se à atuação de um sítio eletrônico, quando deveria ser no âmbito geral, com participação e cumprimento por parte de todos os órgãos do poder público.

Dessa maneira, há o descumprimento do que foi estipulado pelo art. $7^{\circ}$ do Decreto 7.724/2012, o qual prevê a disponibilização das informações nos sites de órgãos e entidades do Poder Executivo federal brasileiro (BRASIL, 2012). Assim, ocorre a concentração das informações no Portal da Transparência, e não a capilarização das informações pelos sites dos órgãos e entidades do Poder Executivo federal brasileiro, havendo, em primeira e simples análise, uma falha na aplicação da LAI nesse aspecto.

Apesar de se defender neste trabalho que a prática ideal a ser adotada pelos órgãos do Poder Executivo seria a consonância dos respectivos portais institucionais com as diretrizes da LAI, não se pode deixar de ressalvar que a reunião das informações em um único site pode trazer vantagens do ponto de vista das facilidades do acesso ao cidadão. Isso porque, em vez de navegar e procurar informações por páginas distintas, pode ser mais fácil dirigir-se a uma única porta de entrada para obter acesso a serviços e informações públicas.

Nesse sentido, o Decreto $n^{\circ}$ 9.756/2019 instituiu o portal único “gov.br” no âmbito dos órgãos e das entidades da administração pública federal direta, autárquica e fundacional do Poder Executivo federal, por meio do qual as informações institucionais, notícias e serviços públicos prestados pelo governo federal serão disponibilizados de maneira centralizada. Ademais, o decreto dispõe sobre as regras de unificação dos canais digitais do governo federal (BRASIL, 2019a). Seguindo o mesmo raciocínio, a Organização para a Cooperação e Desenvolvimento Econômico (OCDE), a pedido do governo brasileiro, desenvolveu uma Revisão do Governo Digital, a qual direciona para a realização da priorização de uma sólida política de entrega de serviços digitais que permitiria ao governo brasileiro mudar o panorama do país, deixando gradativamente de ser centrado nas instituições e em suas práticas, de modo que a prestação de serviços seja orientada ao usuário, a partir de uma postura proativa “[...] que seja capaz de fornecer os serviços de forma simplificada, 
acessível, inteligente e personalizada” (ORGANIZAÇÃO PARA A COOPERAÇÃO E DESENVOLVIMENTO ECONÔMICO, 2018, p. 22).

Em geral, todos os requisitos presentes na LAI foram preenchidos pela maioria dos portais; todavia, eles são deficitários quanto à inexistência da indicação da categoria da passagem, nos casos de viagens dos servidores dos órgãos. De igual forma, não há disponibilização, na área das licitações, de atalho para solicitação, por meio de correio eletrônico, de informações adicionais. Embora o Brasil conte com o respaldo legislativo, além da sociedade civil e outros atores-chave, como jornalistas, para a luta contra a corrupção no país e estímulo da reutilização de dados governamentais abertos e de informação do setor público para a cocriação de valor (ORGANIZAÇÃO PARA A COOPERAÇÃO E DESENVOLVIMENTO ECONÔMICO, 2018, p. 19), na prática, a ausência de mecanismos de acesso prejudica a ciência do cidadão quanto a importantes dados públicos e fragiliza ainda mais a democracia, já que essa categoria, além de envolver vultosas somas, ainda concentra preocupantes problemas em razão das reiteradas situações de corrupção envolvendo empresas privadas prestadoras de serviços públicos no Brasil.

Tais falhas são exemplo do descumprimento da orientação de requisitos necessários na seção transparência, estipulados em lei (BRASIL, 2012), a destacar: licitações realizadas e em andamento, com editais, anexos e resultados, bem como contratos firmados e notas emitidas; remuneração e subsídio recebidos por ocupante de cargo, posto, graduação, função e emprego público, incluídos os auxílios, ajudas de custo e proventos de aposentadoria e pensões de servidores e empregados públicos na ativa.

Além disso, não há, na maioria dos portais, área que atente sobre a Lei de Acesso à Informação (“Legislação/Lei de Acesso à Informação”). Isso denota o expresso não atendimento ao modelo estabelecido pela Secretaria de Comunicação Social da Presidência da República, o qual prevê a necessidade de uma ferramenta que venha a redirecionar o usuário para a página do Portal Brasil e para o site sobre a Lei de Acesso à Informação (BRASIL, 2012).

Especificamente a respeito do site da Presidência da República, observa-se que este não cumpre os objetivos de acesso à informação, tendo seus itens esparsos e mal organizados. Não há aba com as perguntas frequentes dos internautas, tampouco ações e programas, uma vez que a única mensagem, ao abrir a página, é “Atualmente não existem itens nessa pasta”. O portal não trata sobre receitas. Ademais, nem sequer menciona o horário de atendimento do órgão/entidade, uma vez que apenas remete à legislação acerca de jornada de trabalho dos servidores públicos federais. Além disso, não menciona “participação social”. Também não apresenta relatórios estatísticos de atendimento à LAI, nem autoridade responsável pelo monitoramento e implementação da lei. 
A ausência desses dados revela certo descaso com a efetivação da LAI, pois não disponibiliza meios para que o cidadão acesse as informações mais básicas referentes ao funcionamento do próprio órgão e ao responsável pelas informações, condição de possibilidade sem a qual não logrará obter as demais informações públicas que poderá estar buscando. A Presidência da República, como representação máxima do Poder Executivo, deveria servir de exemplo para os demais órgãos, e não ser o mais deficitário. O que se observa é a saliência de dados e ações que inclinam o usuário a enxergar o lado positivo do governo, denotando expresso caráter político no acesso à informação e ocultamento a outros dados, cujo cerne está na transparência e controle do cidadão.

Além dos dados coletados empiricamente, merece relevo o período de permutas e instabilidade jurídica que o Brasil enfrenta nessa seara. No Brasil, a Lei ${ }^{\circ} 13.844$, de 18 de junho de 2019 (BRASIL, 2019b), que trata da organização básica dos órgãos da Presidência da República e dos ministérios e foi oriunda da Medida Provisória (MP) 870/2019 (BRASIL, 2019d), definiu que a administração pública federal, que tinha 29 pastas ministeriais, passasse para 22, sendo 16 ministérios, quatro estruturas vinculadas à Presidência da República, Advogado-Geral da União (AGU) e Banco Central (BC). Salienta-se a extinção dos seguintes ministérios: Cidades; Cultura; Desenvolvimento Social; Esportes; Fazenda; Indústria, Comércio Exterior e Serviços; Integração Nacional; Planejamento, Desenvolvimento e Gestão; Segurança Pública; e Trabalho.

Ademais, foram criadas outras pastas ministeriais, que assumiram os antigos ministérios extintos, como é o caso do Ministério da Economia, que acolheu funções dos Ministérios da Fazenda, Planejamento e Indústria. O Ministério do Trabalho passou a ser distribuído em três pastas: Economia, Justiça e Cidadania. Já o Ministério da Cultura passou para o Ministério da Cidadania (BRASIL, 2019b).

A Lei $n^{0} 13.844 / 2019$ não tardou a sofrer alteração, pela Lei ${ }^{0} 13.901$, de 11 de novembro de 2019 (BRASIL, 2019c), que teve origem na MP 886/2019 (BRASIL, 2019e). Com a conversão em lei, algumas preocupantes mudanças que haviam sido adotadas, pelas medidas provisórias, com relação às comunidades tradicionais foram revistas. A Fundação Nacional do Índio (Funai), que havia migrado do Ministério da Justiça para o Ministério da Mulher, Família e Direitos Humanos, foi devolvida ao Ministério da Justiça. Ademais, a competência para a identificação, delimitação e demarcação de terras indígenas, que havia sido transferida à alçada do Ministério da Agricultura, Pecuária e Abastecimento, retornou igualmente ao Ministério da Justiça. 
O que se nota, até então, é que uma série de alterações, acréscimos e vetos foram realizados. Salienta-se que esse cenário de mudança gera preocupação, não somente diante das severas modificações estruturais que estão ocorrendo - e que, em muitos casos, voltam ao status quo pouco após a nova orientação - nesse breve lapso temporal, como também, com o possível intuito de generalizar e aglutinar pastas ministeriais. O posicionamento defendido nesta pesquisa é o de que, caso se diminuam os órgãos do Poder Executivo, as matérias não serão contempladas da mesma maneira pormenorizada. Diante da adoção dessa política, pode-se pensar que há um saldo positivo ao cidadão que terá menos portais para navegar, sendo facilitado o acesso à informação. Todavia, não basta o acesso à informação, mas o acesso integral e completo aos dados. Assim, o (já muitas vezes falho) acesso à informação passa a ser prejudicado, uma vez que o cidadão, além de nem sequer conseguir acompanhar ou entender as alterações nessa rápida permuta, pode vir a ter acesso a um conteúdo reduzido de informações, sendo ainda mais dificultosa a concretização da transparência ativa.

Passa-se ao estudo comparado no âmbito da Argentina, que também sofreu, recentemente, uma série de rupturas nas suas pastas ministeriais. O país vizinho possui uma confiança no governo consideravelmente superior à do Brasil, além de entender diferentemente a questão da corrupção, não sendo essa uma das suas preocupações centrais (LATINOBARÓMETRO, 2018). A fim de compreender esse contexto latino-americano, focando nesses dois países, a próxima seção do artigo visa verificar como ocorre a efetivação da transparência ativa na Argentina.

\subsection{ANÁLISE DOS DADOS CONTIDOS NOS PORTAIS INSTITUCIONAIS DO PODER EXECUTIVO ARGENTINO}

No âmbito da Argentina, foram selecionados vinte portais institucionais, além do site da presidência: Ministerio de Agroindustria; Ministerio de Ambiente y Desarrollo Sustentable; Ministerio de Ciencia, Tecnología e Innovación Productiva; Ministerio de Cultura; Ministerio de Defensa; Ministerio de Desarrollo Social; Ministerio de Energía y Minería; Ministerio de Hacienda; Ministerio de Finanzas; Ministerio del Interior, Obras Públicas y Viviendas; Ministerio de Educación; Ministerio de Justicia y Derechos Humanos; Ministerio de Modernización; Ministerio de Producción; Ministerio de Relaciones Exteriores y Culto; Ministerio de Salud; Ministerio de Seguridad; Ministerio 
de Trabajo, Empleo y Seguridad Social; Ministerio de Transporte; Ministerio de Turismo e Casa Rosada (esta última, relacionada à presidência da Argentina).

No decorrer da pesquisa, todavia, houve redução dos ministérios do país, com a fusão e a extinção de alguns, e a incorporação, como secretarias, de outros. A maioria dos sites das novas secretarias mantiveram o layout, a estrutura e informações de quando possuíam o status de ministério; por isso, inicialmente se optou por manter a abrangência da pesquisa nos vinte ministérios propostos, uma vez que as análises de grande parte deles já havia sido realizada quando da mudança. Entretanto, com relação ao Ministerio de Finanzas, houve uma alteração significativa no site, com redução completa do conteúdo, razão pela qual foi eliminado da pesquisa, que passou a abranger os dezenove ministérios restantes, além do site da Presidencia de la Nación.

Do estudo, verificou-se que os ministérios da Argentina possuem uma padronização. No âmbito do Plano Nacional de Governo Eletrônico, o Decreto 378 estabelece, desde 2005, em seu artigo $5^{\circ}$, diversos programas a serem adotados pelos órgãos vinculados ao poder público argentino. Todos esses programas visam à transparência na divulgação de seus atos, incluindo um portal geral do Governo da República Argentina, que permite o acesso a informações da administração pública de forma ágil e simples via internet (ARGENTINA, 2005), o que é verificado por meio da padronização dos sites argentinos.

Em todos os sites havia o denominador comum chamado “Transparência”, que dá acesso às informações constantes na Lei de Acesso à Informação. Geralmente, no menu “Transparencia”, há o item "Ver toda la información de transparencia deste organismo", que direciona para uma seção específica de transparência, organizada de forma semelhante em todos os ministérios e que contém grande parte das informações encontradas na pesquisa.

Os sites também disponibilizam informações e dados, majoritariamente, pelos formatos .pdf e .doc, cumprindo o requisito de que os portais institucionais devem conter informações completas e atualizadas, em formato digital e dados abertos (ARGENTINA, 2016), a fim de tornar possível a manipulação desses dados pelo interessado. Além disso, estão padronizados quanto às licitações e contratações, pois remetem ao mesmo site - aquelas ao site “compr.ar”, estas ao site “contrat.ar”. Há alguns ministérios que, além dessa possibilidade de acesso à informação, também fornecem link próprio para verificar os contratos e licitações, dentro da própria página.

Não foram encontradas informações acerca das "Perguntas frequentes". Tampouco informações classificadas, nem classificação por grau de sigilo. Observa-se, contudo, que as diretrizes a serem seguidas pelos órgãos da administração pública argentina, listadas nos incisos do artigo 32 da LAI argentina (ARGENTINA, 2016), incluem a publicação de um rol de informações em seus 
sites, adotado como patamar mínimo de transparência no país, e, diferentemente do Brasil, não apreciam tais itens na legislação.

Por sua vez, positivamente, os ministérios do Poder Executivo argentino apresentam o “Serviço de informação ao cidadão (SIC)”, mediante o link “Pedinos información”, atendendo quase integralmente ao requisitos do questionário de estudo, pecando somente, na maior parte dos casos, quanto à presença de relatórios estatísticos de acesso à Lei de Acesso à Informação. No que se refere à transparência passiva, o artigo $9^{\circ}$ da LAI argentina garante a possibilidade de solicitação de informações por escrito ou por meios eletrônicos, sem qualquer formalidade, sendo suficiente a identificação e os dados de contato do solicitante e a identificação clara da informação solicitada (ARGENTINA, 2016), o que ocorre nos sites em apreço.

Com relação ao item "Ver registros de obsequios y viajes de funcionários” consta o link que contém as informações de viagens, denominado "Viajes financiadas por terceiros”. Nele há um item denominado “Erogación del Estado Nacional”, ou seja, "Subsídio do Estado Nacional”. Em alguns dos casos, constam viagens custeadas pelo Estado, razão pela qual marcou-se como existente a informação a respeito das despesas do órgão com diárias e passagens pagas a servidores públicos em viagens a trabalho ou a colaboradores eventuais em viagens do interesse da administração, nos itens preenchidos. Noutros, no entanto, há somente informações de viagens custeadas por terceiros, casos em que não se preencheu o requisito do formulário.

As despesas são geralmente divulgadas no item "Presupuesto", dentro da seção de transparência ativa. As informações relacionadas aos empregados contratados encontram-se no item “Autoridades y personal”, sendo que na maioria dos casos há um link no rodapé desta página com a lista dos empregados para ser baixada, contendo outras informações que variam de ministério para ministério, tais como a modalidade de contratação e o regime jurídico.

Cada ministério possui sua peculiaridade, havendo vídeos, links de acesso a programas, ações e metas. Diferente dos demais sites dos ministérios do Poder Executivo que foram analisados, a página da Presidência Argentina não atende ao objetivo do direito ao acesso à informação de maneira satisfatória. O portal presidencial parece focar nos pontos positivos do país, mostrando, por exemplo, arquivos com os últimos discursos, eventos de destaque e estrutura do palácio do governo. Assim, destaca-se que o referido site não apresenta link de acesso à informação, já que no item “Información” não há os dados de transparência necessários. Não há acesso à seção específica sobre a LAI, nem informações claras quanto à prestação de serviços ao cidadão (apesar de mostrar os trâmites principais, não é feito da mesma forma detalhada como nos ministérios), nem participação social, auditorias, convênios, despesas, receitas, licitações ou contratos. Tampouco lista os 
empregados terceirizados, servidores, perguntas frequentes, SIC ou demais informações classificadas. Apresenta somente o organograma parcialmente detalhado, agenda presidencial e ações e programas. Um ponto positivo de destaque, no entanto, é a existência de item na página principal de acessibilidade, o qual apresenta as seguintes facilitações: teclado para navegação, comandos de voz, emissões de sons pelo microfone, leitor de tela próprio, Think to command (utilização da mente para navegar) e botões de acessibilidade.

Pode-se compreender o Poder Executivo como aquele que é um dos mais exigidos para dar respostas rápidas às questões de ordem prática (DALLARI, 1996, p. 3-5). Nesse sentido, verifica-se o esforço legal de ambos os países em análise, para impulsionar o acesso à informação. À exceção do portal da Presidência da República Argentina - que, assim como o do Brasil, apresenta severas falhas de transparência, a demonstrar um preocupante descumprimento e falta de exemplo desses núcleos de informação -, a Argentina cumpre muitos dos requisitos presentes em sua LAI. Não só possui portais padronizados, como também, possibilita o contato facilitado do usuário com os serviços basilares, e, em muitos casos, acesso aos dados pertinentes de cada órgão.

Não obstante o satisfatório resultado encontrado, apontadas as lacunas oriundas do descumprimento de alguns pontos da lei específica, é impossível desvincular o campo da pesquisa da realidade fática oriunda das constantes decisões e mudanças políticas, desde o início do estudo até então. Com efeito, tanto o Brasil quanto a Argentina vêm sofrendo uma série de alterações na sua organização administrativa, fruto de articulações governamentais dos representantes desses países. Na Argentina, em setembro de 2018, reduziu-se de 23 para 10 o número de ministérios. Fundiram-se vários deles, sob a justificativa de reduzir a crise econômica que o país atravessa. Pastas como a do trabalho e da agroindústria passaram a ser secretarias. Além disso, o ministério da saúde foi integrado ao de desenvolvimento social. Ademais, os ministérios de cultura e ciência se uniram ao de educação. Nesse ponto, acrescenta-se uma nota de pesar, pois cada um desses ministérios tinha competências específicas, e a agregação de tantos conteúdos sob um mesmo comando pode gerar a perda de identidade, com reflexos negativos para cada uma dessas áreas.

Percebe-se, portanto, que além dos explícitos descumprimentos de alguns requisitos das leis de acesso à informação pelos países analisados, em especial nos portais da presidência da república de ambos países, a redução de ministérios pode ser preocupante para o acesso e transparência de informações. Embora não tenham sido apuradas as consequências dessas alterações - que por um lado podem ser vistas positivamente, na medida em que são diminuídas as estruturas administrativas, gerando possíveis ganhos de eficiência e de escala na oferta de serviços e de informações, já que o cidadão, em vez de navegar por inúmeras páginas eletrônicas, poderia encontrá-las em um número 
reduzido de páginas -, acredita-se que a aglutinação de pastas ministeriais venha a potencializar a generalidade dos dados e a supressão de informações.

Sob o risco de transformar as informações em puro marketing, alheias à realidade, indo contra os preceitos da administração pública voltada à eficiência e responsabilidade pelos recursos públicos (GRUMAN, 2012, p. 107), os cidadãos, se inviabilizados de participarem dos processos decisivos do governo, ao menos devem fiscalizar a forma com que as informações vêm sendo dispostas, para que se assegure o pleno cumprimento das LAI nesses países cuja governamentalidade vem pondo em xeque as estruturas democráticas. Por isso, os avanços legais devem ser acompanhados de análise crítica da realidade fática. Tanto a Argentina quanto o Brasil apresentam resultados parcialmente satisfatórios quanto ao cumprimento efetivo da transparência ativa. Embora exista esse movimento de combate à corrupção e facilitação do acesso à informação, as recentes mudanças políticas devem ser vistas com atenção, para que não passe despercebido qualquer sinal de retrocesso.

\section{CONCLUSÃO}

Mediante a presente pesquisa buscou-se, por meio de abordagem comparativa, responder se os sites do Poder Executivo argentino e brasileiro atendem às exigências de transparência delineadas pelas respectivas leis de cada país. O direito à informação consiste em um elemento indispensável para o pleno funcionamento de um Estado democrático de direito, já que viabiliza o diálogo entre o povo e seus governantes.

Como as Tecnologias da Informação e da Comunicação (TIC) favorecem o exercício desse direito, cabe aos Estados potencializarem a transparência governamental. Tanto no Brasil quanto na Argentina as Leis de Acesso à Informação (LAI) e demais decretos presidenciais visam delinear um patamar mínimo de transparência a ser atingido pelos sujeitos obrigados, com informações que devem integrar as páginas dos portais institucionais de forma completa, atualizada e em local de fácil acesso ao usuário - critérios que nem sempre são observados na prática.

Primeiro, quanto ao Brasil, assevera-se que apesar de a maioria dos requisitos terem sido preenchidos, não houve a divulgação dos gastos com as passagens, nos casos de viagens dos servidores dos órgãos; não existe, na área das licitações, atalho para solicitação de dados adicionais por meio de correio eletrônico; tampouco há, na maioria dos portais, área que atente sobre a Lei de Acesso à Informação (“Legislação/Lei de Acesso à Informação”). Especificamente a respeito do site da Presidência da República, os requisitos da LAI não são cumpridos, já que não existe aba com as perguntas frequentes dos internautas; não são divulgadas ações e programas; o horário de atendimento 
do órgão/entidade não está indicado; faltam relatórios estatísticos de atendimento à LAI; tampouco a autoridade responsável pelo monitoramento e implementação da lei é informada.

Quanto à Argentina, observou-se que há padronização institucional dos portais, havendo acesso à aba com informações de transparência e disponibilização de dados para download, além de acesso a site relacionado a compras e licitações. No entanto, não foram encontradas informações acerca das “Perguntas frequentes”, e inexistem informações classificadas ou classificação por grau de sigilo (estas, talvez por não haver obrigatoriedade conforme a lei argentina). O portal presidencial argentino também é extremamente desproporcional aos dos ministérios e, tal como o do Brasil, deficitário. Nele não há link de acesso à informação; os dados de transparência exigidos por lei não são disponibilizados; tampouco proporciona acesso à seção específica sobre a LAI ou informações claras de prestação de serviços ao cidadão. Vários itens importantes são inexistentes, tais como participação social, auditorias, convênios, despesas, receitas, licitações ou contratos, e sequer há lista com os empregados terceirizados, servidores, perguntas frequentes, SIC ou demais informações classificadas.

Ademais, os países estudados estão sendo marcados, atualmente, por uma série de decisões governamentais um tanto quanto perigosas às jovens democracias. O Brasil - a partir de janeiro de 2019 - e a Argentina - a partir de setembro de 2018 - reduziram drasticamente suas pastas ministeriais. Isso deve ser visto com muita atenção, já que o acúmulo de funções e atribuições, dada à fusão e extinção de pastas ministeriais, pode vir a dificultar a transparência e o acesso a informações pelo cidadão. Não basta existir a informação, ela deve ser condizente com a realidade, clara e de fácil acesso aos que a buscam, algo que, infelizmente, tem parcial cumprimento por esses dois Estados mercosulinos.

\section{REFERÊNCIAS}

ACKERMAN, John M.; SANDOVAL, Irma E. Leyes de Acceso a la Información en el mundo. Cuadernos de Transparencia, 07. Delegación Coyoacán, México, D.F.: Instituto Federal de Acceso a la Información Pública, 2005.

ALFARO, Griselda. Situación sobre el derecho de acceso a la información pública en Argentina (2010-2012). Revista Académica de la Federación Latinoamericana de Facultades de Comunicación Social, [s. l.], n. 87, jul./dez. 2013. Disponível em: https://bit.ly/2xPpnzz. Acesso em: 10 mar. 2019.

ARGENTINA. Constitución de la Nación Argentina. Ley n. 24.430 - Ordénase la publicación del texto oficial de la Constitución Nacional (sancionada en 1853 con las reformas de los años 1860, 
1866, 1898, 1957 y 1994). 15 dez. 1994. Disponível em: https://bit.ly/3cQ0BOP. Acesso em: 2 jun. 2018.

ARGENTINA. Decreto 1172/2003. Apruébanse los Reglamentos Generales de Audiencias Públicas para el Poder Ejecutivo Nacional, para la Publicidad de la Gestión de Intereses en el ámbito del Poder Ejecutivo Nacional, para la Elaboración Participativa de Normas, del Acceso a la Información Pública para el Poder Ejecutivo Nacional y de Reuniones Abiertas de los Entes Reguladores de los Servicios Públicos, Formularios de inscripciones, registro y presentación de opiniones y propuestas. Establécese el acceso libre y gratuito vía Internet a la edición diaria del Boletín Oficial de la República Argentina. 3 dez. 2003. Disponível em: https://bit.ly/2XSHTBP. Acesso em: 10 mar. 2019.

ARGENTINA. Decreto 378/2005, de 27 de abril, sobre el Plan Nacional de Gobierno Electrónico y Planes Sectoriales de Gobierno Electrónico. Boletín Oficial, 28 de abril de 2005, Buenos Aires, 27 de abril de 2005. Disponível em: https://bit.ly/3cCwABO. Acesso em: 9 mar. 2019.

ARGENTINA. Ley n. 27.275, de 14 de septiembre de 2016. Derecho de acceso a la información pública. 14 set. 2016. Disponível em: https://bit.ly/2Kpup8v. Acesso em: 12 fev. 2019.

ASSEMBLEIA GERAL DAS NAÇÕES UNIDAS. Declaração Universal dos Direitos Humanos. 1948. Disponível em: https://bit.ly/3btYGPD. Acesso em: 18 jun. 2018.

ASSEMBLEIA GERAL DAS NAÇÕES UNIDAS. Pacto Internacional sobre os Direitos Civis e Políticos. 16 dez. 1966. Disponível em: https://bit.ly/2zndjGd. Acesso em: 18 jun. 2018.

BAUMAN, Zygmunt; LYON, David. Vigilância líquida. Tradução Carlos Alberto Medeiros. Rio de Janeiro: Zahar, 2013.

BRASIL. Constituição da República Federativa do Brasil de 1988. Diário Oficial da União, Brasília, DF, 5 out. 1988. Disponível em: https://bit.ly/34DqD4X. Acesso em: 2 jun. 2018.

BRASIL. Decreto de 3 de abril de 2000. Institui Grupo de Trabalho Interministerial para examinar e propor políticas, diretrizes e normas relacionadas com as novas formas eletrônicas de interação.

Diário Oficial da União, Brasília, DF, 4 abr. 2000. Disponível em: https://bit.ly/2yvqZ1n. Acesso em: 24 fev. 2019.

BRASIL. Decreto n. 5.687, de 31 de janeiro de 2006. Promulga a Convenção das Nações Unidas contra a Corrupção, adotada pela Assembléia-Geral das Nações Unidas em 31 de outubro de 2003 e assinada pelo Brasil em 9 de dezembro de 2003. Diário Oficial da União, Brasília, DF, 1 fev. 2006. Disponível em: https://bit.ly/2Kqr217. Acesso em: 2 jul. 2019.

BRASIL. Decreto n. 7.724, de 16 de maio de 2012. Regulamenta a Lei no 12.527, de 18 de novembro de 2011, que dispõe sobre o acesso a informações previsto no inciso XXXIII do caput do art. 5o, no inciso II do § 3o do art. 37 e no § 2o do art. 216 da Constituição. Diário Oficial da União, Brasília, DF, 1 fev. 2006. Disponível em: http://www.planalto.gov.br/ccivil_03/_ato20112014/2012/Decreto/D7724.htm. Acesso em: 5 mar. 2019.

BRASIL. Decreto n. 8.638, de 15, de janeiro de 2016. Institui a Política de Governança Digital no âmbito dos órgãos e das entidades da administração pública federal direta, autárquica e fundacional. 
Diário Oficial da União, Brasília, DF, 18 jan. 2016a. Disponível em: https://bit.ly/3cwgHge. Acesso em: 8 mar. 2019.

BRASIL. Decreto n 9.756, de 11 de abril de 2019. Institui o portal único "gov.br” e dispõe sobre as regras de unificação dos canais digitais do Governo federal. Diário Oficial da União, Brasília, DF, 11 abr. 2019a. Disponível em: https://bit.ly/3bu0d8l. Acesso em: 19 nov. 2019.

BRASIL. Lei n. 12.527, de 18 de novembro de 2011. Regula o acesso a informações previsto no inciso XXXIII do art. 5o, no inciso II do § 3o do art. 37 e no § 2o do art. 216 da Constituição Federal; altera a Lei no 8.112, de 11 de dezembro de 1990; revoga a Lei no 11.111, de 5 de maio de 2005, e dispositivos da Lei no 8.159, de 8 de janeiro de 1991; e dá outras providências. Diário Oficial da União, Brasília, DF, 18 nov. 2011 - Edição extra. Disponível em: https://bit.ly/2wZWJeB. Acesso em: 6 maio 2018.

BRASIL. Lei n. 13.844, de 18 de junho de 2019. Estabelece a organização básica dos órgãos da Presidência da República e dos Ministérios; altera as Leis nos 13.334, de 13 de setembro de 2016, 9.069, de 29 de junho de 1995, 11.457, de 16 de março de 2007, 9.984, de 17 de julho de 2000, 9.433, de 8 de janeiro de 1997, 8.001, de 13 de março de 1990, 11.952, de 25 de junho de 2009, 10.559, de 13 de novembro de 2002, 11.440, de 29 de dezembro de 2006, 9.613, de 3 de março de 1998, 11.473, de 10 de maio de 2007, e 13.346, de 10 de outubro de 2016; e revoga dispositivos das Leis nos 10.233, de 5 de junho de 2001, e 11.284, de 2 de março de 2006, e a Lei $n^{0} 13.502$, de $1^{\circ}$ de novembro de 2017. Diário Oficial da União, Brasília, DF, 18 jun. 2019b - Edição extra. Disponível em: https://bit.ly/3cDvINb. Acesso em: 15 nov. 2019.

BRASIL. Lei n. 13.901, de 11 de novembro de 2019. Altera a Lei $n^{\circ} 13.844$, de 18 junho de 2019, a Lei $n^{\circ} 8.171$, de 17 de janeiro de 1991, a Lei ${ }^{\circ} 12.897$, de 18 de dezembro de 2013, e a Lei ${ }^{\circ}$ 13.334, de 13 de setembro de 2016, para dispor sobre a organização básica dos órgãos da Presidência da República e dos Ministérios. Diário Oficial da União, Brasília, DF, 11 dez. 2019c. Disponível em: https://bit.ly/2VIetDu. Acesso em: 15 nov. 2019.

BRASIL. Medida Provisória n. 870, de $1^{\text {0 }}$ de janeiro de 2019. Estabelece a organização básica dos órgãos da Presidência da República e dos Ministérios. Diário Oficial da União, Brasília, DF, 1 jan. 2019d. Disponível em: https://bit.ly/3eKO7cI. Acesso em: 27 mai. 2019.

BRASIL. Medida Provisória n. 886, de 18 de junho de 2019. Altera a Lei ${ }^{\circ} 13.844$, de 18 junho de 2019, a Lei $n^{\circ} 8.171$, de 17 de janeiro de 1991, a Lei $n^{\circ} 12.897$, de 18 de dezembro de 2013, a Lei $n^{\circ}$ 9.613, de 3 de março de 1998, e a Lei n ${ }^{0} 13.334$, de 13 de setembro de 2016, para dispor sobre a organização básica dos órgãos da Presidência da República e dos Ministérios. Diário Oficial da União, Brasília, DF, 19 jun. 2019e. Disponível em: https://bit.ly/34WsSQH. Acesso em: 15 nov. 2019.

BRASIL. Ministério da Transparência, Fiscalização e Controle. Convenção das Nações Unidas contra a Corrupção. Brasília, DF: MTFC, 2016b. Disponível em: https://bit.ly/2xPIJoc. Acesso em: 2 jul. 2019.

BRASIL. Ministério do Planejamento, Desenvolvimento e Gestão. Governo Eletrônico. Portal de Governo Digital do Brasil. Histórico. Nov 2019f. Disponível em: https://bit.ly/3eHXudh. Acesso em: 8 mar. 2019. 
CARTER CENTER. Declaração de Atlanta e Plano de Ação para o Avanço do Direito de Acesso a Informação. 2008. Disponível em: https://bit.ly/2VsuA9k. Acesso em: 2 jul. 2019.

CENDEJAS JÁUREGUI, Mariana. Evolución histórica del derecho a la información. Derecho Comparado de la Información, [s. l.], n. 10, p. 57-84, jul./dez. 2007. Disponível em: https://bit.ly/3eHx2AC. Acesso em: 17 fev. 2019.

CRUZ-RUBIO, César Nicandro. O que é (e o que não é) governo aberto? Uma discussão conceitual. Revista Temas de Administração Pública, [s. l.], v. 10, n. 1, p. 129-148, 2015. Disponível em: https://bit.ly/2XSMFiJ. Acesso em: 24 fev. 2019.

DALLARI, Dalmo de Abreu. O poder dos juízes. São Paulo: Saraiva, 1996.

GOOGLE. Google Forms. 2019. Disponível em: https://bit.ly/2S0I36f. Acesso em: 20 nov. 2019.

GRUMAN, M. Lei de Acesso à Informação: notas e um breve exemplo. Revista Debates, [s. l.], v. 6, n. 3, p. 97-108, set./dez. 2012.

LATINOBARÓMETRO. Opinión Pública Latinoamericana. Informe Latinobarómetro 2018.9 nov. 2018. Disponível em: https://bit.ly/3eHxXRA. Acesso em: 17 nov. 2018.

LAVALLE COBO, Dolores. Derecho de acceso a la información pública. Buenos Aires: Astrea, 2009.

MARTINUZZO, José Antonio. Governo eletrônico no Mercosul: o retrato segundo os portais federais de e-gov. Revista de Economía Política de las Tecnologías de la Información y Comunicación, [s. l.], v. X, n. 1, jan./abr. 2008. Disponível em: https://bit.ly/2XUjBHo. Acesso em: 9 mar. 2019.

MENDEL, Toby. El Derecho a la Información en América Latina: comparación jurídica. Quito: UNESCO, 2009. Disponível em: https://bit.ly/3at8vfj. Acesso em: 21 jul. 2018.

ORGANIZAÇÃO DOS ESTADOS AMERICANOS. Convenção americana sobre direitos humanos. 22 nov. 1969. Disponível em: https://bit.ly/2x2N7Qo. Acesso em: 21 jul. 2018.

ORGANIZAÇÃO PARA A COOPERAÇÃO E DESENVOLVIMENTO ECONÔMICO (OCDE). Revisão do Governo Digital do Brasil. Rumo à Transformação Digital do Setor Público. Principais conclusões. 30 abr. 2018. Disponível em: https://bit.ly/2XXAscE. Acesso em: 19 nov. 2019.

OYHANARTE, Marta; KANTOR, Mora. El derecho de acceso a la información pública en la Argentina. Un análisis de su situación normativa y su efectividad. In: Poder Ciudadano. Corrupción y Transparencia. Informe 2014. Buenos Aires: Eudeba, 2015. p. 253-280. Disponível em: https://bit.ly/2S2aAsi. Acesso em: 12 fev. 2019.

ROVER, Aires José. A democracia digital possível. Revista Sequência, [s. l.], n. 52, p. 85-104, jul. 2006. Disponível em: https://bit.ly/3arALib. Acesso em: 8 mar. 2019. 
Andrey Oliveira Lamberty Mestrando no Programa de Pós-Graduação em Direito da Universidade Federal de Santa Maria. Especialista em Direito e Processo do Trabalho pela Universidade Franciscana. Bacharel em Direito pelo Centro Universitário Franciscano. Advogado. E-mail: andrey.lamberty@gmail.com

Thais Bonato Gomes Mestranda no Programa de Pós-Graduação em Direito da Universidade Federal de Pelotas. Especialista em Direito e Processo do Trabalho pela Universidade Franciscana. Bacharel em Direito pelo Centro Universitário Franciscano. Advogada. E-mail: thaisbonatog@gmail.com

Rosane Leal da Silva

Doutora em Direito pela Universidade Federal de Santa Catarina. Professora Associada nos cursos de Graduação e Mestrado em Direito da Universidade Federal de Santa Maria e dos cursos de Direito da Universidade Franciscana e da Antonio Meneghetti Faculdade. Coordenadora do Núcleo de Direito Informacional da Universidade Federal de Santa Maria (NUDI).E-mail: rolealdasilva@gmail.com 